\title{
Política de indexação em periódicos da Ciên cia da Informação: um estudo das diretrizes para atribuição de palavras- chave aos artigos
}

\author{
Lais Pereira de Oliveira ${ }^{I}$ \\ http://orcid.org/0000-0001-9092-4204 \\ Mariângela Spotti Lopes Fujita ${ }^{I I}$ \\ http://orcid.org/0000-0002-8239-7114 \\ Paula Regina Dal'Evedove \\ http://orcid.org/0000-0003-1521-2201 \\ Daniel Martínez-ÁvilaIV \\ http://orcid.org/0000-0003-2236-553X
}

${ }^{I}$ Universidade Estadual Paulista Júlio de Mesquita Filho, SP, Brasil.

Doutoranda em Cî̂ncia da Informação.

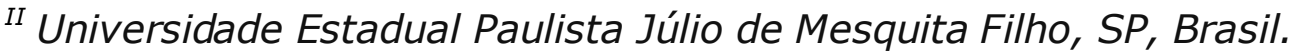

Doutora em Ciências da Comunicação pela Universidade de São Paulo. Atualmente presta serviços voluntários em ensino de pós-graduação, pesquisa e extensão na Faculdade de Filosofia e Ciências da UNESP - Campus de Marília. Docente permanente na Pós-Graduação na linha de pesquisa Produção e Organização da Informação, do Programa em Ciência da Informação da UNESP.

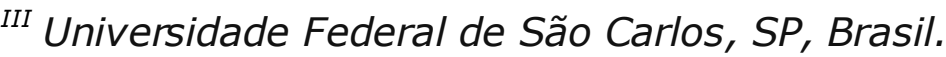

Professora Adjunta do Departamento de Ciência da Informação, Centro de Educação e Ciências Humanas, atuando no curso de Graduação em Biblioteconomia e Ciência da Informação e no Programa de Pós-Graduação em Ciência da Informação.

IV Universidade Estadual Paulista Júlio de Mesquita Filho, SP, Brasil.

Professor Assistente Doutor na Universidade Estadual Paulista.

http://dx.doi.org/10.1590/1981-5344/3876

Aborda a política de indexação em periódicos nacionais da Ciência da Informação. Considera a escassa abordagem 
do assunto, no contexto da comunicação científica, assim como a necessidade pragmática de sistematizar a ação de atribuição de palavras-chave pelo autor da publicação. Objetiva analisar as diretrizes para atribuição de palavras chave aos artigos em processo de submissão. Constitui estudo descritivo, de natureza quali-quantitativa e caráter de pesquisa documental, em razão da coleta dos dados desenvolvida sobre as políticas para publicação e as diretrizes para autores, disponibilizadas pelas revistas. Emprega a técnica de análise de conteúdo, para sistematização dos dados coletados. Os resultados demonstram a existência de diretrizes relacionadas à quantidade de termos, orientadas em sua maioria para a seletividade na indexação. O mesmo não acontece com as especificações sobre a profundidade dos termos e a linguagem de indexação, apesar da breve sinalização para a última, em um conjunto de cinco revistas, adeptas da linguagem controlada. Conclui-se que os periódicos da Ciência da Informação precisam atentar para a instituição de uma política de indexação, a fim de proporcionar maior assertividade aos autores, na atribuição de palavraschave.

Palavras-chave: Atribuição de termos. Indexação de assunto. Política de indexação. Processo de submissão. Periódicos da Ciência da Informação.

\section{Indexing policy of journals on Information Science: a study of the guidelines for assignment of keywords to articles}

This paper analyzes the indexing policies of Brazilian journals on Information Science. It considers the scarce approach to the subject in the context of scientific communication, as well as the pragmatic need to systematize the action of assigning keywords by the author of the publication. It aims to analyze the online 
guidelines for assignment of keywords to articles during the submission process. It is a descriptive research that follows a qualitative and quantitative methodology. It can be characterized as a documentary research as the data was collected from the publication policies and guidelines for authors that are made available by the journals. We also conducted a content analysis to systematize the collected data. The results reveal the existence of guidelines related to the number of terms, mostly connected to selection in indexing. This was not the case for the specifications of the depth of terms and the indexing language, despite the referral to the latter in a total of five journals that use a controlled language. We conclude that Brazilian journals of Information Science need to pay a greater attention to the implementation of indexing policies in order to provide a greater assertiveness to the authors, especially during the attribution of keywords.

Keywords: Assignment of terms. Subject indexing. Indexing policy. Submission process. Journals on Information Science.

Recebido em 27.02.2019 Aceito em 07.12.2020

\section{Introdução}

A representação de assunto é prática cotidiana de bibliotecários, no âmbito do tratamento temático da informação. Pode ser vista como "uma combinação metodológica altamente estratégica entre o tratamento do conteúdo de documentos e sua recuperação por um usuário" (FUJITA, 2003, p. 61). Mas, a indexação não se efetiva apenas pelas mãos de profissionais, como preconiza Lancaster (2004, p. 7):

Embora a indexação e redação de resumos fossem antigamente tidas como processos que somente interessavam a bibliotecas e a algumas editoras, sua relevância e utilidade são reconhecidas hoje em dia de modo muito mais amplo, pois, obviamente, encontram aplicação em todos os tipos de recursos de informação em formato digital. 
Durante o autoarquivamento de um documento em um repositório digital, a publicação de um conteúdo web ou a submissão de artigos em portais de revistas, a indexação é necessária para viabilizar a recuperação por assunto. O sujeito que passa por alguma das situações acima descritas é orientado a atribuir palavras-chave para representar os assuntos do recurso informacional com o qual lida.

Além disso, vale ressaltar que a indexação de assunto se manifesta de várias formas, sobretudo no contexto web. É entendida enquanto ação de constituição de índices, como processo de representação de assunto pela atribuição de termos a um documento, mas também - no universo das publicações científicas - como a forma segundo a qual artigos são incluídos em bases de dados, sendo estas "um dos canais responsáveis pela coleta e disseminação da informação contida nos periódicos científicos" (ANDREATTO, 2010, p. 6).

Os periódicos científicos envolvem uma dinamicidade de ações direcionadas aos editores - que desempenham um papel central, na comunicação da ciência (MIRANDA; PEREIRA, 1996) - mas também aos autores das produções, quando no processo de submissão. Ao produzir um artigo científico e selecionar o periódico no qual deseja publicar, o autor se vê às voltas com diretrizes e normativas para adequação e formatação do seu texto. Uma delas diz respeito à construção das palavras-chave - representativas do conteúdo do artigo - a serem incluídas nos metadados e no próprio corpo do texto, logo após o resumo.

Tendo em vista a democratização do ato de indexar e a amplitude de manifestações e entendimentos sobre o mesmo, assim como a necessidade de padronização desse processo, para uma melhor recuperação entre autores e leitores/usuários do sistema, abre-se uma ampla margem de possibilidades de investigação. O estudo em questão direciona-se justamente à compreensão da indexação de assunto conduzida por autores, no âmbito da publicação científica e em função dos critérios postos para tal. Nesse sentido, tem-se como problemática: quais as diretrizes para atribuição de palavras-chave aos artigos em processo de submissão, nos periódicos brasileiros de Ciência da Informação?

A área de Ciência da Informação (CI) foi escolhida, por dedicar-se, naturalmente, a práticas de organização com foco na recuperação da informação por assunto. Assim, o objetivo central de analisar as diretrizes para atribuição de palavras-chave aos artigos em processo de submissão, nos periódicos dessa área, pressupõe por si só uma sistematização diferenciada da que ocorre em outros campos. Além disso, considera-se a escassez de literatura científica nesse tema (FUJITA; AGUSTÍN-LACRUZ; TERRA, 2018). 
Investigações sobre avaliação de periódicos científicos comumente se voltam aos aspectos bibliométricos, envolvendo indicadores de desempenho. É o caso, por exemplo, de Appel et al. (2020), que definiram indicadores, ferramentas e metodologias de avaliação de desempenho para a Revista Latino-Americana em Avaliação do Ciclo de Vida. O mesmo se vê em Silva, Almeida e Grácio (2018), os quais propuseram a avaliação de periódicos pela combinação do fator de impacto e do índice $h$; também em Marcondes e Mendonça (2006), que desenvolveram um método de avaliação para periódicos de ciência e tecnologia; e em Gomes e Santos (2001), os quais avaliaram a qualidade científica de periódico na área de Medicina Tropical.

Em trabalho mais direcionado à perspectiva que ora se desenvolve, Dias e Cervantes (2013) discutem o tratamento temático da informação em periódicos científicos de Biblioteconomia e Ciência da Informação nacionais e internacionais. As autoras, entretanto, se dedicam especificamente às linguagens e instrumentos documentários adotados para a organização temática dos artigos, levantados a partir de questionário eletrônico e formulário estruturado de coleta. Outra investigação correlata, de autoria de Fujita, Agustín-Lacruz e Terra (2018), englobou periódicos de Ciência da Informação e de Comunicação indexados no Journal Citation Reports (JCR). As autoras, por sua vez, analisaram diretrizes existentes sobre título, resumo e palavras-chave.

Registra-se que o foco inicial recaia sobre as políticas de indexação utilizadas pelos periódicos brasileiros de Ciência da Informação. Na sua ausência, transferiu-se para as orientações disponibilizadas pelos periódicos aos autores, em busca de normativas minimamente voltadas à instrução sobre a atribuição de palavras-chave. Desse modo, ainda levando em conta a lacuna existente em torno de tal abordagem, o presente estudo contribui com a via teórica da indexação, na medida em que estabelece discussões orientadas para além do espectro tradicional da representação de assunto, conduzida por bibliotecários. Em termos práticos, possibilita enxergar ações postas sutilmente aos autores, quando da atribuição de termos a seus artigos, dando visibilidade aos elementos que orientam essa questão e permitindo pensá-la nos termos como acontece. Além disso, colabora com o aperfeiçoamento das políticas de indexação de revistas científicas, levando a uma descrição temática mais assertiva pelos autores dos trabalhos e a uma recuperação mais efetiva nas bases de dados, trazendo contribuições ao próprio processo de comunicação científica. 


\section{Um olhar sobre a comunicação científica, os periódicos e a indexação}

A ciência se consolida pela produção de conhecimento científico, a qual, por sua vez, se efetiva na prática da comunicação científica. O ato de publicar um artigo em um periódico, depois do desenvolvimento de um estudo, representa a chance de apresentar tal produto àqueles que comungam do campo investigado.

A comunicação científica representa, afinal, um meio de dialogar com o público, isto é, com sua comunidade científica (VALERIO; PINHEIRO, 2008). E os periódicos são instrumentos direcionados a essa finalidade, com a função de disseminar informação, bem como de dar visibilidade aos autores e editores, tanto quanto à própria instituição (SILVEIRA et al. 2018).

De certo modo, "as revistas científicas ocupam, hoje, um lugar central nos modos de organização e troca entre as comunidades científicas e acadêmicas" (GOMES, 2010, p. 167). Agem, portanto, enquanto importante elo para fazer chegar ao cientista dados e informações que favorecem a produção de novos conhecimentos.

O periódico científico, que existe há mais de 300 anos (GOMES, 2013) e é "conhecido e reconhecido desde sempre como o canal de comunicação formal, essencial para a Ciência, mantém o seu papel, independentemente de suas transformações ao longo do tempo e das polêmicas atuais" (PINHEIRO, 2012, p. 139). O periódico é, também, um dos canais para obtenção de "informações bibliográficas para trabalhos de cunho científico" (SEVERINO, 2014, p. 134).

Ao pensar no aspecto da indexação de assunto em periódicos, logo se remete para a ideia de inclusão das revistas em uma base de dados, ação que favorece a divulgação e amplifica a visibilidade das produções científicas. Entretanto, o ato de indexar, na verdade, também está presente na forma de indexação de assunto, desde o advento do periódico científico, pela composição de índices e resumos.

Historicamente, transformações impactaram as revistas científicas, surgindo a necessidade de controle e divulgação das publicações. Desse modo, no final do século XIX, irrompem métodos dedicados à superação dos problemas de acesso à literatura disponível, nessa época, por meio do uso de resumos e índices (ANDREATTO, 2010).

A composição de índices e resumos, por conseguinte, representou a potencialização do acesso à informação, uma vez que permitiu publicizar o que era publicado à época, nas revistas científicas. Estas, aliás, evoluíram para o suporte digital e passaram a reunir recursos de pesquisa e navegação até então não viáveis no meio físico. Todavia, as publicações 
científicas digitais ainda são embasadas no modelo das publicações impressas (MARCONDES, 2011).

Pensando especificamente na indexação de assunto, enquanto processo da representação temática da informação, deve-se ressaltar que:

os novos documentos digitais propiciam acesso ao texto sem que seja necessária a indexação. Entretanto, os serviços de indexação continuam a existir comprovando que a organização e representação do conhecimento são importantes para a recuperação da informação, principalmente no mundo científico e tecnológico, uma vez que é necessária a especificidade na seleção de conteúdos. (FUJITA, 2012, p. 19)

O portal de periódicos em si é uma forma de organização das produções científicas (RODRIGUES; FACHIN, 2008). Entretanto, não representa a especificidade temática de cada publicação nele contida, apenas favorece sua disposição e armazenamento. Em função disso, existe a prática dos periódicos de solicitar a indexação, pela inserção das palavras-chave que melhor caracterizem os assuntos abordados nos artigos publicados. Tal temática tem suscitado pesquisas diversas (MIGUÉIS et al., 2013). Até porque estudar o uso de palavras-chave e de instrumentos documentários em periódicos científicos é importante, a fim de que estes cumpram, de fato, seu papel e atendam aos objetivos específicos das distintas comunidades de usuários (DIAS; CERVANTES, 2013).

Segundo Aquino e Aquino (2013, p. 229), "o termo Palavras-chave refere-se às palavras mais importantes do texto científico utilizadas pelos autores, para indexação". Fujita, Agustín-Lacruz e Terra (2018) reiteram que, assim como título e resumo, as palavras-chave são elementos essenciais da representação do conhecimento.

Mais do que isso, enquanto mecanismos tradicionais na Documentação, palavras-chave orientam usuários leigos sem domínio da terminologia da área, permitindo buscar e recuperar informações. Os termos acabam, assim, por assumir um valor pragmático considerável, na medida em que representam nódulos cognitivos referentes ao conteúdo (SANTIAGO, 2009).

A palavra-chave pode, ainda, ser transformada em um descritor, marcadamente padronizado e com controle de linguagem. Nesse sentido, "a primeira não obedece a nenhuma estrutura, é aleatória e retirada de textos de linguagem livre. Para uma palavra-chave tornar-se um descritor, ela tem que passar por um rígido controle de sinônimos" 
(BRANDAU; MONTEIRO; BRAILE, 2005, p. 8), oportunidade na qual se empregam vocabulários controlados.

As palavras-chave compostas irão, então, para os metadados que o autor preenche na plataforma da revista, na ocasião de submissão e, também, para o corpo do próprio texto que ele escreveu, aparecendo logo após o resumo do artigo e auxiliando em sua representação. Afinal, "hoje em dia os próprios autores são responsáveis por fornecer os elementos de representação do documento (título, resumo e palavras-chave) de seus trabalhos, e os metadados das revistas científicas estão disponíveis eletronicamente" (FUJITA; AGUSTÍN-LACRUZ; TERRA, 2018, p. 322, tradução nossa).

Em suma, portanto, palavras-chave são "termos vocabulares retirados dos documentos e que correspondem a uma escolha dos autores" (MIGUÉIS et al., 2013, p. 115), podendo ainda ser substituídas por descritores com controle semântico-linguístico. Por meio delas, aumenta-se a probabilidade de que o artigo seja encontrado por motores de busca (SERRA; FERREIRA, 2014), especialmente porque, ao utilizá-las, o acesso ao conteúdo documental é potencializado para além do conjunto expresso no título e no resumo, traduzindo o pensamento dos autores (MIGUÉIs et al., 2013).

Tendo em vista as políticas editoriais dos periódicos, deve-se ressaltar que estas englobam diretrizes para os autores, as quais são particularmente relevantes (FUJITA; AGUSTÍN-LACRUZ; TERRA, 2018). Há que se considerar, porém, "o enfoque controverso sobre as normas estabelecidas por revistas científicas para publicação" (AQUINO; AQUINO, 2013, p. 229), incluindo as que se referem à composição das palavras chave que acompanharão o resumo, assim como sua natureza e utilidade (SMIRAGLIA, 2013). Essa situação acaba por evidenciar a importância de estudos que tragam constatações e ampliem a discussão a respeito, principalmente com aportes da política de indexação.

\section{A composição dos termos e a política de indexação}

Em bases gerais, por conta da periodicidade e dos rigorosos processos de revisão por pares, periódicos científicos permitem disseminar conhecimento de maneira atualizada e confiável (RODRIGUES; FACHIN, 2008). É o mundo editorial que "estabelece as formas de publicação e distribuição do conhecimento" (FUJITA; AGUSTÍN-LACRUZ; TERRA, 2018, p. 321, tradução nossa). Idealmente, esse rígido sistema de publicação e divulgação científica deve, necessariamente, ter o mesmo empenho e cuidado com relação à organização e representação das informações em seu âmbito.

Os periódicos científicos precisam se voltar a questões relacionadas à organização e padronização da informação científica (RODRIGUES; 
FACHIN, 2008). É fato que referências e resumos passam a ser disponibilizados nas bases de dados, assim como os artigos em texto completo, o que já facilita o acesso (ANDREATTO, 2010).

Mas, além dessa questão, é importante ressaltar a coexistência de "vários modelos de representação e de recuperação da informação [...] como o recurso a termos extraídos diretamente da linguagem natural, em que se inserem as expressões utilizadas pelos próprios autores no título, resumo e texto integral" (MIGUÉIS et al., 2013, p. 115). Isto é, atribuemse palavras-chave caracterizadoras de cada artigo publicado, mas sem controle de vocabulário. Ou ainda, por meio do uso de softwares estatísticos, como WordStat, adotado para extrair termos do texto (SMIRAGLIA, 2013).

Desse modo, é fundamental atentar para a atribuição de palavras-chave aos artigos que compõem cada edição lançada pelos periódicos científicos, já que, juntamente com o resumo, funcionarão como representações do todo, ou seja, do texto completo. Sobretudo porque, apesar de as palavras-chave serem a menor seção escrita em um artigo, seu uso não é padronizado entre as revistas (AQUINO; AQUINO, 2013), o que resulta em falhas na representação de assunto e, consequentemente, na recuperação.

Ao se empregar termos representativos do texto, garante-se uma seleção mais apropriada da informação contida nos artigos científicos, posto que "as palavras-chave também são usadas pelos motores como indexadores, sendo um elemento fundamental quando fazemos a busca de bibliografia" (SERRA; FERREIRA, 2014, p. 5). Além disso, apesar de toda a tecnologia representada por portais de periódicos disponíveis na Internet, o que se vê muitas vezes são sérias dificuldades na busca por informações, em razão de um grande número de publicações isoladas que não permitem busca integrada e uma recuperação eficaz (RODRIGUES; FACHIN, 2008).

No que diz respeito à formatação técnica do texto, periódicos comumente estabelecem normativas para publicação dos artigos, tendo o autor que tomar ciência destas para, então, submeter seu trabalho (SEVERINO, 2014). Há, portanto, uma prática comunicativa, mas também pedagógica, presente na divulgação do conhecimento científico (SANTIAGO, 2009), até em razão do caráter instrutivo que permeia o universo de produção e comunicação científicas. Ambas as questões reforçam a necessidade de racionalização nas ações das revistas, especialmente no que concerne à construção das palavras-chave que favorecem a própria difusão das produções científicas lançadas.

Logo, a política de indexação pode ser uma via importante para se pensar na sistematização dessa ação de atribuição de termos aos artigos científicos, garantindo a coexistência dos aspectos comunicativos e 
pedagógicos da ciência, a que alude o autor supracitado. Inclusive porque, de acordo com Andrade e Sabbag (2017, p. 82), a política "não é apenas uma formalidade para os profissionais, mas um guia útil que demonstra a direção". Desse modo, pode agregar ao contexto da publicação científica, especificando critérios para caracterização de assunto nesse âmbito.

Um meio segundo o qual a política pode ser observada é o manual de indexação, que representa sua documentação oficial (FUJITA; RUBI, 2006). A política de indexação é tida justamente como um conjunto de orientações reguladoras da indexação, e precisa ser considerada em todos os sistemas de informação nos quais o ato de indexar está presente. Decorre desse contexto a importância de perscrutar não apenas a indexação, mas a própria política do sistema de informação (RUBI; FUJITA, 2003), esteja ele onde estiver.

A política de indexação representa o estabelecimento de diretrizes e normativas para o processo de indexação, estando sua determinação ligada à otimização de serviços (GUIMARÃES, 2000). Sendo a indexação elemento inerente ao tratamento temático biblioteconômico, mas também, ao ato de submissão científica em periódicos, há que se pensar na sua regulação em tal contexto, a fim de que a atribuição de termos pelos autores aconteça orientada pelos princípios teóricos e metodológicos da representação da informação por assunto.

Em texto clássico sobre política de indexação, Carneiro (1985) destaca que esta envolve a racionalização de processos. Conforme a autora, uma série de elementos devem ser definidos na política, especialmente no que concerne ao processo de indexação. Fujita e Santos (2016) tratam da elaboração de um manual contendo orientações gerais e específicas, estas últimas contemplando o processo de indexação, a linguagem e a avaliação.

A formalização em um manual garante que a política de indexação seja devidamente difundida e enxergada, inclusive dando clareza à sistemática do ato de indexar e às instâncias a ele inerentes. Como observam Fujita e Santos (2016, p. 63), "o processo de indexação como elemento essencial da política é, por sua vez, influenciado pelas variáveis da recuperação da informação: escolha da linguagem, exaustividade, especificidade, revocação e precisão".

A quantidade e a abrangência dos termos definidos para a indexação são aspectos centralmente importantes, os quais determinam o uso de mais ou menos palavras, de teor geral ou específico. Além disso, o fato de o processo ser exaustivo ou seletivo, com maior ou menor nível de especificidade, concorrerá diretamente na revocação ou na precisão, durante a busca pela informação.

Rubi e Fujita (2003, p. 70) explicitam que "tanto a exaustividade como a especificidade são elementos que devem estar claramente 
definidos na política do sistema de informação, pois exercerão influência direta sobre a indexação realizada". Esse aspecto, entretanto, também não tem sido suficientemente explorado e precisaria ser mais abordado nos estudos de organização do conhecimento (SIMÕES et al., 2018).

A linguagem é outra importante questão na política de indexação, podendo ela ser natural ou controlada. No caso da primeira, também entendida como linguagem livre, empregam-se palavras dos próprios autores, presentes nos títulos ou mesmo no texto. Já a controlada permite maior consistência, posto que parte de um vocabulário pré-estabelecido, para essa atribuição.

Nessa medida, palavras-chave refletem termos oriundos da linguagem natural cotidianamente utilizada, enquanto descritores configuram termos com controle de linguagem. Em outras palavras, 0 estabelecimento de um descritor de assunto ocorre pelo uso de um vocabulário controlado.

O vocabulário controlado pode assumir a forma de um tesauro, que é um instrumento com relacionamentos semânticos e controle de sinônimos, do qual se extraem os termos de indexação. "As bases de dados documentárias costumam dispor de um vocabulário controlado para a indexação de documentos" (GIL LEIVA, 2012, p. 98). O mesmo, porém, parece não acontecer de modo sistematizado nas revistas científicas, cenário este que reforça a necessidade da pesquisa em questão.

Em bases gerais, a política de indexação tem como foco a orientação e a regulação da indexação de assunto em unidades de informação. Entretanto, deve ser cuidadosamente estabelecida junto às normativas de publicação das revistas e, embora norteando apenas questões essenciais para o delineamento dos termos - quanto à quantidade, abrangência, linguagem e vocabulário - a política de indexação pode garantir relevante auxílio a quem submete suas produções científicas e, na maior parte das vezes, não possui conhecimento suficiente sobre a prática de representação por assuntos.

Consequentemente, o estabelecimento da política de indexação pode viabilizar uma maior assertividade na seleção e recuperação dos artigos de periódicos, essencialmente, porque a existência de uma política completa e formal possibilita padronizar a forma de atribuição dos termos e interiorizar processos decisórios relacionados à própria representação temática, ainda que fora do contexto informacional tradicional.

\section{Metodologia}

O estudo é descritivo, de natureza quali-quantitativa e com caráter de pesquisa documental, porque se presta à descrição analítico-expositiva dos fatos observados. Compreende aspectos estatísticos e interpretativos, na discussão dos resultados, conduzidos a partir do corpus documental, 
na forma de diretrizes para autores, disponibilizadas na página online das revistas científicas investigadas.

Os periódicos brasileiros de Ciência da Informação foram o foco da presente investigação. Analisando-se o escopo de cada um, a aderência ao campo supracitado e a existência de um fluxo normal de publicação, com base na "Lista de Periódicos Nacionais de Ciência da Informação Classificados no Qualis Capes", elaborada por Jonathas Carvalho, para o portal Biblioo Cultura Informacional, obteve-se um total de 30 revistas.

Para a seleção dos documentos analisados, verificaram-se os sites das revistas brasileiras de Ciência da Informação, mediante leitura e análise das seções "Sobre a revista" e "Edições". Constatou-se a convergência de alguns periódicos para outras áreas que não especificamente a Ciência da Informação - congregando, de modo mais amplo, o campo da comunicação ou da tecnologia - e a descontinuidade de alguns números, caracterizada pelo atraso no fluxo de publicação.

Desse modo, atendidos os critérios de escopo, aderência temática e fluxo ativo, acima listados, procedeu-se à coleta dos dados com base documental em cada um dos 30 periódicos selecionados (vide Tabela 1), no período de 21 a 23 de novembro de 2018, a partir do acesso ao menu "Sobre a revista".

Tabela 1 - Periódicos analisados.

\begin{tabular}{|c|c|c|c|}
\hline Nome & Periodicidade & Vinculação & Qualis \\
\hline Biblionline & Trimestral & Departamento de Ciência da Informação da UFPB & $\overline{\mathrm{B} 1}$ \\
\hline $\begin{array}{l}\text { Bibliotecas } \\
\text { Universitárias }\end{array}$ & Semestral & Biblioteca Universitária da UFMG & $\overline{\mathrm{C}}$ \\
\hline Biblos & Semestral & Instituto de Ciências Hu manas e da Informação da FURG & B3 \\
\hline $\begin{array}{l}\text { Brazilian Journal of } \\
\text { Information Science }\end{array}$ & Trimestral & $\begin{array}{l}\text { Programa de Pós-Graduação em Ciência da Informação } \\
\text { da UNESP/Marília }\end{array}$ & B1 \\
\hline Ciência da Informação & Quadrimestral & $\begin{array}{l}\text { Instituto Brasileiro de Informação em Ciência e } \\
\text { Tecnologia (IBICT) }\end{array}$ & B1 \\
\hline $\begin{array}{l}\text { Ciência da Informação } \\
\text { em Revista }\end{array}$ & Quadrimestral & $\begin{array}{l}\text { Programa de Pós-Graduação em Ciência da Informação } \\
\text { da UFAL }\end{array}$ & $\overline{\mathrm{B} 5}$ \\
\hline Em Questão & Quadrimestral & Programa de Pós-Graduação em Co mun icação da UFRGS & $\mathrm{A} 2$ \\
\hline Encontros Bibli & Quadrimestral & $\begin{array}{l}\text { Programa de Pós-Graduação em Ciência da Informação } \\
\text { da UFSC }\end{array}$ & $\overline{\mathrm{A} 2}$ \\
\hline Folha de Rosto & Semestral & $\begin{array}{l}\text { Programa de Pós-Graduação em Bib lioteconomia da } \\
\text { UFCA }\end{array}$ & B5 \\
\hline $\begin{array}{l}\text { Informação e } \\
\text { Informação }\end{array}$ & Quadrimestral & $\begin{array}{l}\text { Programa de Pós-Graduação em Ciência da Informação } \\
\text { do Departamento de Ciência da Informação da UEL }\end{array}$ & A2 \\
\hline Informação e Sociedade & Quadrimestral & $\begin{array}{l}\text { Programa de Pós-Graduação em Ciência da } \\
\text { Informação da UFPB }\end{array}$ & $\bar{A} 1$ \\
\hline $\begin{array}{l}\text { Informação e } \\
\text { Tecnologia }\end{array}$ & Semestral & $\begin{array}{l}\text { Associação Nacional de Pesquisa e Pós-Graduação em } \\
\text { Ciência da In formação (ANCIB) }\end{array}$ & B5 \\
\hline Informação em Pauta & Semestral & $\begin{array}{l}\text { Departamento de Ciências da Informação e do Programa } \\
\text { de Pós-Graduação em Ciência da Informação da UFC }\end{array}$ & B5 \\
\hline
\end{tabular}




\begin{tabular}{|c|c|c|c|}
\hline Informação@Profissões & Semestral & $\begin{array}{l}\text { Programa de Pós-Graduação em Ciência da Informação } \\
\text { da UEL }\end{array}$ & B5 \\
\hline Liinc em Revista & Semestral & $\begin{array}{l}\text { Instituto Brasileiro de Informação em Ciência e } \\
\text { Tecnologia (IBICT) }\end{array}$ & B1 \\
\hline $\begin{array}{l}\text { Múltiplos Olhares em } \\
\text { Ciência da Informação }\end{array}$ & Semestral & Escola de Ciências da Informação da UFMG & B5 \\
\hline $\begin{array}{l}\text { Perspectivas em } \\
\text { Ciência da Informação }\end{array}$ & Trimestral & Escola de Ciência da Informação da UFMG & A1 \\
\hline $\begin{array}{l}\text { Pesquisa Brasileira em } \\
\text { Ciência da Informação } \\
\text { e Biblioteconomia }\end{array}$ & Semestral & $\begin{array}{l}\text { Editada pelo Grupo de Pesquisa Informação e Inclusão } \\
\text { Social (CNPq), é publicada no Portal de Periódicos da } \\
\text { UFPB }\end{array}$ & B1 \\
\hline Ponto de Acesso & Trimestral & Instituto de Ciência da in formação (ICI) da UFBA & B1 \\
\hline Revista $A C B$ & Quadrimestral & Movimento as sociativo de bibliotecários & B2 \\
\hline $\begin{array}{l}\text { Revista Analisando em } \\
\text { Ciência da Informação }\end{array}$ & Semestral & $\begin{array}{l}\text { Centro de Ciências Biológicas e Socia is Aplicadas da } \\
\text { UEPB }\end{array}$ & B5 \\
\hline $\begin{array}{l}\text { Revista Brasileira de } \\
\text { Biblioteconomia e } \\
\text { Documentação }\end{array}$ & Quadrimestral & $\begin{array}{l}\text { Federação Brasileira de Associações de Bibliotecários, } \\
\text { Cientistas da Informação e Instituições (FEBAB) }\end{array}$ & B1 \\
\hline $\begin{array}{l}\text { Revista Brasileira de } \\
\text { Educação em Ciência } \\
\text { da Informação }\end{array}$ & Semestral & $\begin{array}{l}\text { Associação Brasileira de Educação em Ciência da } \\
\text { Informação (ABECIN) }\end{array}$ & B5 \\
\hline $\begin{array}{l}\text { Revista Conhecimento } \\
\text { em Ação }\end{array}$ & Semestral & $\begin{array}{l}\text { Curso de Biblioteconomia e Gestão de Unidades de } \\
\text { Informação (CBG) da Faculdade de Administração e } \\
\text { Ciências Contábeis (FACC) da UFRJ } \\
\end{array}$ & B5 \\
\hline $\begin{array}{l}\text { Revista de Ciência da } \\
\text { Informação e } \\
\text { Documentação }\end{array}$ & Semestral & $\begin{array}{l}\text { Faculdade de Filos ofia, Ciências e Letras de Ribeirão } \\
\text { Preto (FFCLRP) da USP }\end{array}$ & B1 \\
\hline $\begin{array}{l}\text { Revista de Informação, } \\
\text { Memória e Tecnologia }\end{array}$ & Semestral & $\begin{array}{l}\text { Programa de Pós-Graduação em Ciência da Informação } \\
\text { da UFPE }\end{array}$ & B3 \\
\hline $\begin{array}{l}\text { Revista Digital de } \\
\text { Biblioteconomia e } \\
\text { Ciência da Informação }\end{array}$ & Quadrimestral & Sis tema de Bibliotecas da UNICAMP (SBU) & B1 \\
\hline $\begin{array}{l}\text { Revista Ibero- } \\
\text { Americana de Ciência } \\
\text { da Informação }\end{array}$ & Quadrimestral & Faculdade de Ciência da Informação (FCI) da UnB & B1 \\
\hline $\begin{array}{l}\text { Tendências da Pesquisa } \\
\text { Brasileira em Ciência } \\
\text { da Informação }\end{array}$ & Semestral & $\begin{array}{l}\text { Associação Nacional de Pesquisa e Pós-Graduação em } \\
\text { Ciência da In formação (ANCIB) }\end{array}$ & $\mathrm{B} 1$ \\
\hline TransInformação & Trimestral & $\begin{array}{l}\text { Pontifícia Universidade Católica de Campinas (PUC- } \\
\text { Campinas) }\end{array}$ & A1 \\
\hline
\end{tabular}

Fonte: Elaborada pelos autores (2019).

Conforme explicita a Tabela 1, tem-se, no universo investigado, um conjunto de revistas em sua maioria de publicação semestral (15 ao todo), vinculadas em grande parte a departamentos, faculdades ou programas de pós-graduação de Ciência da Informação (20 ao todo) e com estrato Qualis B ( 23 ao todo), de acordo com o último ciclo de avaliação (2013-2016). Deve-se ressaltar que, pela nova proposta de Qualis Periódicos, em debate com a comunidade acadêmico-científica (COORDENAÇÃO..., 2019) e, dessa forma, ainda não oficializada, são abrangidas mais categorias e alguns estratos se modificarão. 
Os periódicos examinados são, portanto, canais de comunicação sólidos, regulares e estruturados, responsáveis por lançar, a cada edição, uma série de novos artigos científicos. Nesse sentido, acabam por viabilizar, diretamente, a produção de novos conhecimentos no campo científico da Ciência da Informação.

A princípio, os processos de coleta e análise dos dados foram orientados para a busca de uma política de indexação formalmente estabelecida. Posteriormente, na ausência desta, procedeu-se à prospecção sobre as políticas para publicação e as diretrizes para autores, disponibilizadas nas páginas online das revistas. A técnica de análise de conteúdo auxiliou na sistematização, dentre o conjunto documental levantado, das normativas efetivamente relacionadas à atribuição de palavras-chave aos artigos científicos, bem como na tessitura analíticointerpretativa, para atendimento ao objetivo central da pesquisa, apresentada a seguir.

\section{Análise e interpretação dos dados}

A pesquisa objetivou analisar as diretrizes para atribuição de palavras-chave aos artigos em processo de submissão, nos periódicos brasileiros de Ciência da Informação. Dessa maneira, observou-se inicialmente a presença da política de indexação.

Constatou-se que apenas um dos periódicos investigados apresenta um documento formal dessa natureza. Trata-se da Revista Digital de Biblioteconomia e Ciência da Informação (RDBCI), do Sistema de Bibliotecas da Universidade Estadual de Campinas (SBU/UNICAMP), com sua "Política de uso dos Tesaurus e Vocabulários Controlados para Indexação".

O fato de a RDBCI estar associada à biblioteca universitária da UNICAMP é, em certa medida, preponderante para a estruturação, instituição e disponibilização de uma política de indexação aos autores em processo de submissão de artigos, em seu portal, porque o contato com a indexação - entende-se - é ainda mais direto, já que a revista é produzida no contexto biblioteconômico propriamente dito.

Apesar da existência da política de indexação na RDBCI ser um fato extremamente positivo - sobretudo por ser a única com essa preocupação, em um universo de 30 revistas científicas analisadas notou-se que o documento se restringe a listar procedimentos para uso dos vocabulários controlados autorizados para a indexação de assunto. Uma ampliação, portanto, incluindo o processo decisório estabelecido para outras instâncias da constituição de termos, é importante, já que certas variáveis, como escolha da linguagem, exaustividade, especificidade, revocação e precisão, também influem na política. Isso contribuirá, ainda, 
para um padrão de representação de assunto ainda maior, por parte dos autores que submetem seus artigos a essa revista.

Em seguida, verificou-se que, nos demais periódicos analisados, as normativas para publicação encontram-se dispersas na seção "Sobre a revista". Englobam, assim, distintas instruções aos autores, envolvendo aspectos de formatação do texto, indicação de autoria, construção do resumo, uso de tabelas e quadros, forma das referências, entre outros. Falta, por conseguinte, nessas 29 revistas, um documento individual detalhado de como fazer a indexação de assunto pela constituição das palavras-chave representativas do artigo, conforme se observou na RDBCI.

Como os periódicos disseminam conhecimento científico, de forma atualizada (RODRIGUES; FACHIN, 2008), compreende-se que uma maior acurácia no estabelecimento de diretrizes para a atribuição de palavraschave ampliaria sobremaneira esse caráter, ao passo que dinamizaria o acesso por assunto aos artigos publicados, de sorte que os autores poderiam se certificar de utilizar termos mais bem constituídos e mais regulados, em função das orientações de tais diretrizes.

Pela centralidade dos editores de revista no processo de comunicação científica (MIRANDA; PEREIRA, 1996), mostra-se oportuna uma prerrogativa comum, por parte desse grupo, no sentido de evidenciar a importância da escolha e inclusão de palavras-chave em artigos científicos, além, obviamente, da influência dessa ação na conjuntura de pesquisa, produção e publicação científica como um todo. Com efeito, as palavras-chave aumentam a probabilidade de localização do artigo por motores de busca (SERRA; FERREIRA, 2014), ajudando na divulgação da própria revista científica.

Dando sequência à investigação, pela prospecção conjunta sobre políticas para publicação e diretrizes para autores, foi possível identificar alguns critérios mínimos para elaboração das palavras-chave dos artigos submetidos. Como frisado acima, estes estavam sinalizados juntamente com regras relativas a todos os outros elementos a serem observados para a submissão do texto, sem individualização desse aspecto de atribuição de termos, a partir de uma política de indexação, à exceção da RDBCI.

Relativamente à quantidade de palavras-chave a serem empregadas pelo autor, na indexação de assunto, constatou-se que boa parte das revistas científicas analisadas indicam essa delimitação. O gráfico abaixo apresenta os percentuais: 
Gráfico 1 - Indicação da quantidade de palavras-chave.

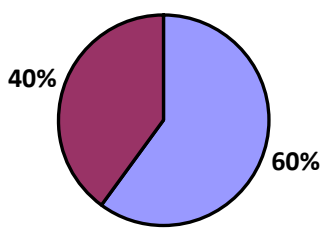

Fonte: Elabora do pelos autores (2019).

Como demonstra o Gráfico 1, em 18 revistas científicas ou 60\% do total, há essa especificação acerca do número de palavras-chave, compreendendo: Biblionline, Bibliotecas Universitárias, Brazilian Journal of Information Studies, Ciência da Informação, Encontros Bibli, Informação e Informação, Informação em Pauta, Liinc em Revista, Múltiplos Olhares em Ciência da Informação, Perspectivas em Ciência da Informação, Ponto de Acesso, Revista ACB, Revista Analisando em Ciência da Informação, Revista Brasileira de Biblioteconomia e Documentação, Revista de Ciência da informação e Documentação, Revista Digital de Biblioteconomia e Ciência da Informação, Revista Ibero-Americana de Ciência da Informação e TransInformação.

Em outras 12 revistas (40\%), contudo, não há qualquer detalhamento dessa ordem para os autores que submetem seus trabalhos, quais sejam: Biblos, Ciência da Informação em Revista, Em Questão, Folha de Rosto, Informação e Sociedade, Informação e Tecnologia, Informação@Profissões, Pesquisa Brasileira em Ciência da Informação e Biblioteconomia, Revista Brasileira de Educação em Ciência da Informação, Revista Conhecimento em Ação, Revista de Informação, Memória e Tecnologia e Tendências da Pesquisa Brasileira em Ciência da Informação.

Majoritariamente, a Ciência da Informação demonstra preocupação com o tratamento temático fixado no âmbito das publicações científicas nacionais, na medida em que sinaliza ao pesquisador a necessidade de se ater a uma quantidade de palavras-chave na complementação do resumo de seu artigo científico. Dias e Cervantes (2013) já haviam evidenciado a regra comum, observada nos 22 periódicos investigados, de que se determinem palavras-chave acompanhando o resumo, ainda que em alguns casos não haja detalhamento a respeito.

Correlacionando tais constatações também com o estudo de Fujita, Agustín-Lacruz e Terra (2018), é possível perceber que, de um total de 32 revistas de Biblioteconomia e Ciência da Informação analisadas pelas 
autoras, 21 delas (65\%) traziam indicações sobre palavras-chave. Em 20 desses periódicos científicos, havia também regras sobre o quantitativo a ser empregado. Predomina, assim, nas duas pesquisas, uma maioria de revistas com especificações acerca do número de palavras-chave para indexação de assunto nos artigos científicos.

Todavia, pela essencialidade das palavras-chave para a representação do conhecimento (FUJITA; AGUSTÍN-LACRUZ; TERRA, 2018), mais do que dimensionar o total de termos, é igualmente importante aferir exaustividade e seletividade concedidas a partir de tal delimitação, entre as 18 revistas que a estabelecem. Acerca da explicitação formal do quantitativo de palavras-chave verificaram-se casos em que é apontado um número mínimo ou máximo delas, conforme demonstrado no gráfico a seguir:

Gráfico 2 - Exaustividade, seletividade e quantidade de termos.

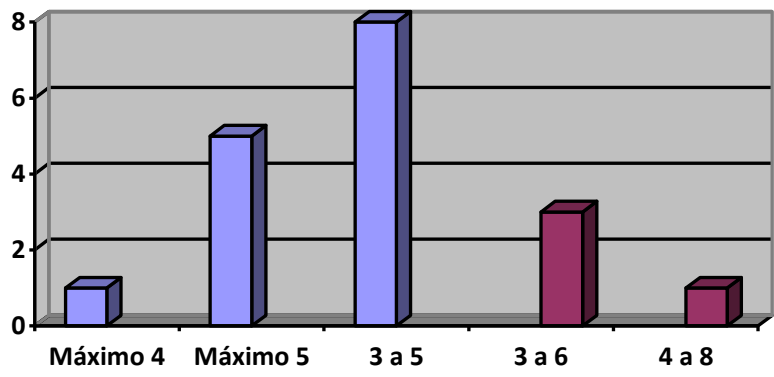

Fonte: Elaborado pelos autores (2019).

Conforme os dados do Gráfico 2, predominam entre os periódicos brasileiros de Ciência da Informação aqueles que indicam uma menor quantidade de palavras-chave para os artigos (14 ao todo), ou seja, uma indexação mais seletiva. Poucas revistas (4 ao todo) sinalizam para o emprego de um maior número de termos, culminando em uma indexação exaustiva.

Cabe destacar que exaustividade e seletividade são elementos fundamentais na política de indexação, e o fato de estarem explicitados em 60\% dos 18 periódicos reforça a preocupação, no contexto da comunicação científica da Ciência da Informação brasileira, com a representação por assunto de artigos científicos. Entretanto, um expressivo número de 12 periódicos não possue recomendações a respeito do quantitativo de palavras-chave a serem utilizadas pelos autores que submetem seus trabalhos.

Há que se ressaltar, ainda, que a recomendação acerca da indexação seletiva comumente evidenciada na literatura de 
Biblioteconomia e Ciência da Informação é de até 5 termos, a partir da qual - se extrapolada - a indexação assume características de exaustividade. Apesar disso, entende-se que essa fronteira não pode ser plenamente estabelecida, inclusive, porque é mais comum, no universo pesquisado, a sugestão de um intervalo entre o mínimo e o máximo de palavras-chave (12 ao todo). Em menor número está a indicação da quantidade máxima de termos a serem empregados (6 ao todo), a qual não deve ser extrapolada. A primeira circunstância, nesse caso, pode ser vista como seletiva, se o foco do autor for a menor margem, ou exaustiva, se a opção for pelo limite máximo de palavras.

Ademais, ainda que os 18 periódicos indiquem o quantitativo de palavras-chave a serem empregadas pelo autor com mais ou com menos detalhamento, considera-se positivo por si só o fato de haver tal recomendação. Afinal, mais difícil se torna, quando não se determina nenhuma especificação nesse sentido, conforme se observou no grupo de 12 revistas.

Além disso, por ser o portal uma forma de organização das produções científicas (RODRIGUES; FACHIN, 2008), outros meios intrínsecos precisam amparar esse propósito ordenador dos próprios artigos nele publicados, sendo oportuno o uso das palavras-chave para esse fim.

De modo complementar, a Tabela 2 lista as revistas e o quantitativo de termos recomendado aos autores, na indexação de assunto. Detalhamse, especificamente, os 18 periódicos nos quais é feita a indicação do número de palavras-chave.

Tabela 2 - Quantitativo de termos por periódico.

\begin{tabular}{|c|c|c|c|c|c|}
\hline & $\begin{array}{c}\text { Máxi mo } \\
4\end{array}$ & $\begin{array}{c}\text { Máximo } \\
5\end{array}$ & $\begin{array}{c}\text { De } 3 \\
\text { a } 5\end{array}$ & $\begin{array}{c}\text { De } 3 \\
\text { a } 6\end{array}$ & $\begin{array}{c}\text { De } 4 \\
\text { a } 8\end{array}$ \\
\hline \multicolumn{6}{|l|}{ Biblionline } \\
\hline \multicolumn{6}{|l|}{ Bibliotecas Universitárias } \\
\hline \multicolumn{6}{|l|}{ Brazilian Journal of Information Science } \\
\hline \multicolumn{6}{|l|}{ Ciência da Informação } \\
\hline \multicolumn{6}{|l|}{ Encontros Bibli } \\
\hline \multicolumn{6}{|l|}{ Informação e Informação } \\
\hline \multicolumn{6}{|l|}{ Informação em Pauta } \\
\hline \multicolumn{6}{|l|}{ Liinc em Revista } \\
\hline \multicolumn{6}{|l|}{ Múltiplos Olhares em Ciência da Informação } \\
\hline \multicolumn{6}{|l|}{ Perspectivas em Ciência da Informação } \\
\hline \multicolumn{6}{|l|}{ Ponto de Acesso } \\
\hline \multicolumn{6}{|l|}{ Revista $A C B$} \\
\hline \multicolumn{6}{|l|}{ Revista Analisando em Ciência da Informação } \\
\hline \multicolumn{6}{|l|}{ Revista Brasileira de Biblioteconomia e Documentação } \\
\hline \multicolumn{6}{|l|}{ Revista de Ciência da Informação e Documentação } \\
\hline Revista Digital de Biblioteconomia e Ciência da Informação & & & & & \\
\hline
\end{tabular}


Revista Ibero-Americana de Ciência da Informação

TransInformação

Fonte: Elaborada pelos autores (2019).

Percebe-se, em certa medida, um padrão na indicação do número de termos de indexação pelos periódicos, essencialmente entre os que foram mais sinalizados, quais sejam: máximo 5 , de 3 a 5 e de 3 a 6 . 0 fato de se repetirem pode representar uma concordância a respeito da média adequada de palavras-chave e, até mesmo, um alinhamento das diretrizes relacionadas à representação de assunto, entre boa parte dos periódicos da Ciência da Informação.

De maneira subsequente, prospectou-se a existência de indicações das revistas para o aspecto da especificidade, ou seja, da abrangência ou profundidade dos termos. Percebeu-se que não há explicitamente qualquer sinalização a respeito, apesar da importância de se definir pelo emprego de termos gerais e específicos ou somente de termos específicos - o que auxiliaria significativamente o autor, na escolha de suas palavras chave - esse critério não é delimitado diretamente pelos periódicos.

Em algumas das políticas para publicação e diretrizes para autores, notam-se breves sinalizações a respeito do uso de termos específicos, relevantes, claros, objetivos, representativos e indicativos do conteúdo (vide Quadro 1). Ainda assim, tais informações se encontram dispersas dentre as observações gerais de submissão e sem a devida ênfase sobre o nível de especificidade.

Quadro 1 - Indicações sobre especificidade da indexação.

\begin{tabular}{|l|l|}
\hline \multicolumn{1}{|c|}{ Periódicos } & \multicolumn{1}{c|}{ Observações } \\
\hline Biblionline & $\begin{array}{l}\text { Resguardar o uso de termos específicos de cada área, quando } \\
\text { este não for contemplado pelo tesauro. }\end{array}$ \\
\hline Ciência da Informação & Palavras es sencialmente relevantes. \\
\hline Em Questão & $\begin{array}{l}\text { O título, o resumo e as palavras -chave devem ser claros e } \\
\text { objetivos e designar o que o texto, de fato, produziu, } \\
\text { evitando termos metafóricos, abstratos e subjetivos. }\end{array}$ \\
\hline Encontros Bibli & Palavras-chave que melhor representemo assunto do artigo. \\
\hline Informação e Informação & $\begin{array}{l}\text { Representatividade dos metadados (qualidade do resumo e } \\
\text { palavras-chave). }\end{array}$ \\
\hline Informação e Sociedade & Palavras representativas do conteúdo do trabalho. \\
\hline Informaçáo @ Profissões & Palavras-chave que representamo conteúdo do texto. \\
\hline Múltiplos Olhares em Ciência da Informação & Termos indicativos do conteúdo. \\
\hline Revista Analisando em Ciência da Informação & $\begin{array}{l}\text { O título, o resumo e as palavras-chave devem ser claros e } \\
\text { objetivos e designar o que o texto, de fato, produziu, } \\
\text { evitando termos metafóricos, abstratos e subjetivos. }\end{array}$ \\
\hline
\end{tabular}

Fonte: Elaborado pelos autores (2019). 
Pode-se considerar relevante o fato de haver uma sinalização destinada aos autores para o emprego de termos objetivos e representativos, embora em apenas 9 revistas científicas e de modo um tanto disperso. Contudo, um delineamento pontual acerca do nível de especificidade seria fundamental, até para complementar as especificações relativas à exaustividade e seletividade, conforme o número de palavras-chave. Ainda mais por conta de estas constituírem o grupo de palavras mais importantes do texto científico (AQUINO; AQUINO, 2013), que cumprirão relevante papel na orientação do usuário leigo e alheio à terminologia da área descrita no artigo (SANTIAGO, 2009).

Outrossim, tanto informações sobre exaustividade quanto sobre especificidade devem ser definidas de forma clara (RUBI; FUJITA, 2003). Logo, detalhes sobre a especificidade dos termos, junto às diretrizes dos periódicos, poderiam possibilitar a instrução direta e pontual, se palavras mais amplas e gerais são permitidas e em quais circunstâncias, ou se apenas vocábulos indicativos dos subtemas tratados no artigo são autorizados. Assim igualmente se viabilizaria a compreensão a propósito dos procedimentos a serem observados para atendimento ao critério de especificidade no uso de palavras-chave, com vistas a uma busca e recuperação mais assertiva.

$\mathrm{Na}$ verdade, os periódicos se configuram como um canal de obtenção de informações bibliográficas (SEVERINO, 2014), amparando, assim, a constituição de outros estudos. Por conseguinte, quanto mais assertiva a constituição das palavras-chave nos artigos, mais amplamente se viabilizam tanto a seleção e a busca por assunto quanto o acesso à informação.

Além disso, 3 entre as 9 revistas trazem breves indicações sobre o uso de termos específicos, as quais não correspondem ao grupo de 18 que delimitam o número de palavras-chave, quais sejam: Em Questão, Informação e Sociedade e Informação@Profissões. Essa constatação demonstra a falta de alinhamento entre as definições sobre exaustividade, seletividade e especificidade da indexação de assunto.

Dando sequência ao estudo, no que diz respeito à linguagem a ser utilizada na indexação, constatou-se que somente 5 periódicos $(16,6 \%)$ fazem essa especificação, nas diretrizes para o autor (vide Gráfico 3), delimitando o uso da linguagem controlada para constituição das palavras-chave, a saber: Biblionline, Informação e Informação, Informação em Pauta, Revista Digital de Biblioteconomia e Ciência da Informação e TransInformação. Todas essas revistas científicas figuram também entre as que especificam o número de termos para os artigos, mas apenas as duas primeiras trazem breves apontamentos sobre uso de 
palavras objetivas e representativas, em alusão mais próxima ao nível de especificidade.

Gráfico 3 - Linguagem de indexação.

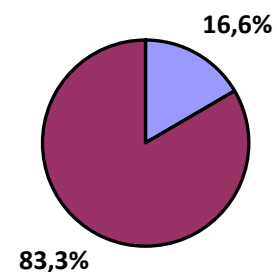

$\square$ Linguagem controlada
$\square$ Não indica

Fonte: Elabora do pelos autores (2019).

O mesmo cenário aqui observado é percebido no estudo de Fujita, Agustín-Lacruz e Terra (2018). Segundo descrevem as autoras, apenas 7 ou $23 \%$ dos periódicos de Biblioteconomia e Ciência da Informação investigados incluíram diretrizes sobre vocabulário controlado para a seleção de palavras-chave. Por sua vez, a pesquisa de Dias e Cervantes (2013) evidenciou, pelos questionamentos feitos aos editores, o uso da linguagem livre por 19 dos 22 periódicos nacionais e internacionais de Ciência da Informação examinados.

Depreende-se, portanto, que não há o devido cuidado das revistas brasileiras da área de Ciência da Informação em sinalizar para os autores a atribuição de termos mediante linguagem natural, questão que, de alguma forma, parece implícita, pela ótica dos periódicos, visto que não se indica nada a respeito da necessidade de consulta a algum vocabulário controlado. Apesar disso, a definição, ainda que pela linguagem natural, seria extremamente importante para permitir aos autores refletirem sobre a atribuição de palavras-chave ao artigo e se organizarem para tal, condicionando-os, aliás, a fazerem sua própria escolha, tendo em vista o texto completo, o resumo ou mesmo o título elaborado para sua produção científica, na determinação de seus termos.

Outrossim, é preciso lembrar que a palavra-chave, em linguagem livre, já não obedece a nenhuma estrutura (BRANDAU; MONTEIRO; BRAILE, 2005), de modo que alguma orientação, especificando meios para sua constituição, seria crucial para haver um mínimo de regulação nessa atribuição temática.

Ao estabelecer o uso de linguagem controlada, concede-se, da mesma maneira, um relevante apoio. Nesse caso, um vocabulário poderia 
ser consultado, trazendo à tona uma série de termos que o autor talvez não tenha levado em conta ou mesmo desconheça, para delimitação temática de sua pesquisa.

Entre as 5 revistas que especificam o uso de linguagem controlada está a Revista Digital de Biblioteconomia e Ciência da Informação, a única a apresentar uma política formal de indexação conforme descrito no início desta seção - e também, a indicar como obrigatória a utilização de linguagem de controle. Nas outras 4, o conjunto de vocabulários controlados mencionado fica a título de sugestão para o autor.

Os outros 25 periódicos $(83,3 \%)$ não trazem qualquer indicação a respeito de vocabulário controlado. Não chegam sequer a explicar se somente a linguagem natural ou a linguagem controlada pode ser utilizada, ou mesmo uma combinação das duas. Simplesmente não há essa informação, no conjunto de diretrizes apresentado. Como o autor é o responsável pelos termos que adota (MIGUÉIS et al., 2013), é relevante haver especificações, mesmo que mínimas, por parte da revista, para auxiliá-lo nessa delimitação e evitar inconsistências.

Por conseguinte, tendo por base as únicas 5 revistas que determinam a utilização de linguagem controlada para construção das palavras-chave, buscou-se observar se havia, nas diretrizes das mesmas, a sugestão de algum vocabulário próprio ou mesmo de um tesauro específico da Ciência da Informação, para uso dos autores. Verificou-se que os periódicos recomendam tanto tesauros nacionais quanto estrangeiros, conforme exposto no gráfico abaixo:

Gráfico 4 - Percentual de tesauros nacionais e estrangeiros.
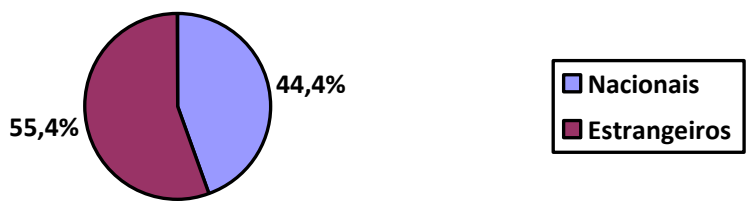

Fonte: Elaborado pelos autores (2019).

Em um universo de 10 tesauros destacados pelas revistas, um se repete (vide Quadro 2): o Tesauro Brasileiro de Ciência da Informação. Dentre os 9 restantes, expressos no Gráfico 4 e que aparecem uma única vez, $5(55,4 \%)$ são estrangeiros e $4(44,4 \%)$ nacionais. O fato de recomendarem vocabulários controlados do Brasil e também de outros 
países pode estar relacionado tanto com o intuito de dar subsídio para a constituição das palavras-chave e das keywords quanto para conceder amplitude temática e gerar mais possibilidades de representação pelos autores dos artigos.

Quadro 2 - Tesauros indicados pelos periódicos.

\begin{tabular}{|c|c|c|}
\hline Periódicos & Tesaur os nacionais & Tesaur os es trangeiros \\
\hline Biblionline & $\begin{array}{l}\text { Tesauro Brasileiro de Ciência da } \\
\text { Informação (IBICT) }\end{array}$ & \\
\hline Informação e Informação & $\begin{array}{l}\text { Vocabulário } \\
\text { Controlado } \\
\text { Informação \& Informação (VCII) } \\
\text { ou tesauros da Ciência da } \\
\text { Informação, caso o termo não } \\
\text { esteja contemplado }\end{array}$ & \\
\hline Informação em Pauta & $\begin{array}{l}\text { Tesauro Brasileiro de Ciência da } \\
\text { Informação (IBICT) } \\
\text { Catálogo de Autoridades da } \\
\text { Biblioteca Nacional }\end{array}$ & $\begin{array}{l}\text { Tesauro de Ciencias de la } \\
\text { Documentación } \\
\text { UN Bibliographic Information } \\
\text { System Thesaurus: UNBIS }\end{array}$ \\
\hline $\begin{array}{l}\text { Revista Digital de Biblioteconomia } \\
\text { e Ciência da Informação }\end{array}$ & $\begin{array}{l}\text { TCI - Tesauro de Ciência da } \\
\text { Informação }\end{array}$ & $\begin{array}{l}\text { Thesauro da UNESCO } \\
\text { Tesauro do ERIC (Education } \\
\text { Resources Information Center) }\end{array}$ \\
\hline TransInformação & & $\begin{array}{llll}\text { Tesauro de } & \text { Ciencias } & \text { de } & \text { la } \\
\text { Documentación (Docutes) } & & \end{array}$ \\
\hline
\end{tabular}

Fonte: Elabora do pelos autores (2019).

Nota-se, pelo quadro acima, que o Tesauro Brasileiro de Ciência da Informação, do Instituto Brasileiro de Informação em Ciência e Tecnologia (IBICT), é sugerido tanto pela Biblionline quanto pela Informação em Pauta, que também aponta outro vocabulário nacional - o Catálogo de Autoridades da Biblioteca Nacional - e mais dois estrangeiros, sendo um em espanhol e outro em inglês. Nesse sentido, pode-se afirmar que a revista abre muitas possibilidades de representação de assunto. No caso de um dado termo não ser localizado em um tesauro, o autor tem a chance de encontrá-lo em outro instrumento ou, ainda, de se deparar com mais de uma forma possível de caracterização para o mesmo tema, mas em idiomas distintos.

Nessa mesma direção está a Revista Digital de Biblioteconomia e Ciência da Informação, a qual traz um tesauro nacional e outros dois estrangeiros. Da mesma forma, amplifica sobremaneira a diversidade de termos possíveis. Informação e Informação também apresenta essa possibilidade, sendo a única a sugerir tanto um vocabulário próprio - o que demonstra o comprometimento com a construção das palavras-chave, quanto tesauros em geral da Ciência da Informação, no caso de o primeiro não ser suficiente. A TransInformação sugere apenas um tesauro para os autores, mas em espanhol. 
A vasta gama de tesauros indicados é um sinal importante do olhar que os periódicos científicos analisados têm para com a constituição das palavras-chave dos artigos. Apesar disso, é muito pouco em relação a todo o espectro que precisa ser pensado e delimitado, em termos de processo decisório, a ponto de resultar em uma política formal e estruturada de indexação capaz de embasar a submissão dos autores à plataforma das revistas, atuando verdadeiramente como um guia (ANDRADE; SABBAG, 2017).

Acresce-se ainda o pequeno número de revistas a estabelecer diretrizes sobre a linguagem para construção dos termos, aspecto que, em alguma medida, sinaliza para a falta de consistência, que pode ser obtida com a linguagem controlada (CARNEIRO, 1985), e mesmo para o pequeno cuidado com a disposição eletrônica desses termos vocabulares (FUJITA; AGUSTÍN-LACRUZ; TERRA, 2018; MIGUÉIS et al., 2013).

Por fim, em continuidade ao estudo, percebeu-se que, além das questões relacionadas à quantidade e profundidade dos termos, linguagem e vocabulário, certas observações postas entre as diretrizes das revistas trazem especificações que acabam por auxiliar os autores na delimitação de suas palavras-chave, conforme descrito no Quadro 3.

Quadro 3 - Observações gerais.

\begin{tabular}{|c|c|}
\hline Periódicos & Observações gerais \\
\hline Ciência da Informação & Não extrair palavras-chave do título. \\
\hline $\begin{array}{l}\text { Revista Brasileira de } \\
\text { Biblioteconomia e Documentação }\end{array}$ & Condições para submissão: limite de 5 descritores. \\
\hline $\begin{array}{l}\text { Revista Digital de Biblioteconomia } \\
\text { e Ciência da Informação }\end{array}$ & $\begin{array}{l}\text { Condições para submissão: certificar-se de que está usando as palavras- } \\
\text { chave padronizadas, de acordo comos tesauros abaixo: } \\
\text { - para termos da língua portuguesa, usar: TCI - Tesauro de Ciência da } \\
\text { Informação. } \\
\text { - para os termos em língua inglesa, usar: Thesaurus UNESCO e/ou ERIC } \\
\text { Thesaurus. }\end{array}$ \\
\hline $\begin{array}{l}\text { Revista Ibero-Americana de } \\
\text { Ciência da Informação }\end{array}$ & $\begin{array}{l}\text { Um termo pode possuir duas ou mais palavras. } \\
\text { Não devem conter palavras que componham o título. }\end{array}$ \\
\hline
\end{tabular}

Fonte: Elaborado pelos autores (2019).

Como é possível observar, no Quadro 3, a especificação para não se empregar palavras do título aparece em dois periódicos. O primeiro deles, a Ciência da Informação; o segundo, a Revista Ibero-Americana. Além dessa sinalização, ressalta-se a possibilidade de uso de termos compostos. Esse tipo de informação sinaliza para o aspecto da estruturação da palavra-chave em si, na medida em que é dado destaque para o que não é válido na sua constituição ou, mesmo, o que pode ser considerado na formação do seu radical. 
A Revista Brasileira de Biblioteconomia e Documentação apenas reforça o número máximo de termos a serem empregados, colocando isso entre as condições para submissão que o autor deve aceitar, no ato do envio do arquivo. A Revista Digital de Biblioteconomia e Ciência da Informação insere, entre tais condições, o uso de palavras-chave padronizadas, a partir de um dos tesauros sugeridos.

Apesar de tais observações, seria fundamental uma formalização dos pontos sinalizados, acompanhada de um maior nível de detalhamento, porque as diretrizes para autores são relevantes e cumprem, afinal, um papel orientativo-normativo essencial a quem submete suas produções e também para a própria padronização procedimental da revista.

Constata-se que algumas das questões postas, enquanto observações gerais, pouco dizem aos autores, já que não explicitam como se deve proceder exatamente na estruturação das palavras-chave, o que deve ser observado e com que critérios se deve fazer a rotulação temática do texto em processo de submissão. Isso se torna ainda mais complicado, ao se ter em vista que o autor do artigo pode ou não ter conhecimento da indexação de assunto e do conjunto de ações técnico-intelectuais que embasam tal atividade.

Afinal, submissões de artigos científicos aos periódicos de CI não se restringem a bibliotecários ou arquivistas. Cada vez mais pesquisadores de outras áreas publicam na Ciência da Informação, os quais não necessariamente compreendem o princípio técnico-intelectual da representação de assunto por trás da atribuição de palavras-chave a um artigo.

Outro aspecto importante a ser mencionado refere-se ao estrato ou fator de impacto dos periódicos do campo. A despeito de essa correlação não ter sido objeto de investigação, percebe-se que, dentre as revistas analisadas, apenas Informação e Sociedade e TransInformação estão indexadas no JCR, enquanto as revistas científicas Ciência da Informação, Informação e Sociedade, Perspectivas em Ciência da Informação e TransInformação são indexadas na base Scopus.

Nesse sentido, observa-se que, tanto no caso dos periódicos de Ciência da Informação indexados no JCR, objeto de investigação de Fujita, Agustín-Lacruz e Terra (2018), quanto nos nacionais, alvo do estudo em questão, aparecem diretrizes para orientação sobre palavras-chave. Essa questão é extremamente positiva, por favorecer - ainda que minimamente - um ponto crucial que diz respeito à delimitação do assunto, capaz de agregar diretamente à recuperação. E isso em um contexto diferenciado, que não o das unidades de informação em seu propósito cotidiano de representar assunto dos mais diversos tipos de materiais, mas, sim, o dos periódicos científicos, inseridos no contexto da publicação e da difusão da ciência. 


\section{Conclusão}

A pesquisa buscou analisar as diretrizes para atribuição de palavras chave aos artigos em processo de submissão, recorrendo para tal à abordagem da política de indexação, em periódicos nacionais da Ciência da Informação. Evidenciou-se a existência de critérios relacionados à quantidade de termos em um número expressivo de revistas da área 18, no total - com destaque para a seletividade, uma vez que a média indicada pela maioria delas é de até 5 palavras que melhor caracterizem o texto.

A mesma ênfase não é dada para a especificidade, sem descrição formal pelos periódicos de Ciência da Informação investigados. Foram observadas apenas indicações aleatórias e dispersas sobre o uso de termos objetivos e representativos, mesmo assim, sem qualquer detalhamento acerca do nível de especificidade a ser adotado. A orientação para uso de termos gerais ou apenas específicos é essencial para garantir uma representação sólida, em consonância com as delimitações sobre a indexação exaustiva ou seletiva, de modo que tal dimensão precisa ser mais bem trabalhada.

Constatou-se ainda que a linguagem para constituição das palavras chave também não recebe a devida atenção, nas diretrizes postas para autores, já que um número baixo de periódicos traz essa informação, indicando o uso da linguagem controlada. Na maioria dos periódicos científicos analisados, não há orientação de qualquer ordem, sequer sinalizando para a utilização de linguagem natural com extração de termos do próprio texto. Os periódicos científicos que possuem especificações a respeito da linguagem controlada também determinam os tesauros a serem empregados para a constituição das palavras-chave, o que é extremamente positivo e demonstra a preocupação com essa ação, pois o cuidado com o controle vocabular é um dos meios para garantir uma adequada recuperação da informação.

Além da pequena abordagem sobre os critérios relacionados ao processo de indexação, em um universo de 30 revistas investigadas, verificou-se que apenas uma possui política de indexação formal. Esse cenário é bastante preocupante, justamente por se tratar de revistas científicas de Ciência da Informação, cujo cerne é justamente a informação e os meios para processá-la, tratá-la e organizá-la, com vistas à sua disseminação.

Levando-se em consideração, por fim, a falta de sistematização específica nas políticas para publicação e nas diretrizes para autores, principalmente para abarcar normativas pontualmente detidas à estruturação de palavras-chave, muito ainda há que ser feito. Sobretudo o envolvimento das revistas científicas da área na elaboração de políticas de 
indexação formalmente estruturadas, a partir dos critérios de exaustividade, especificidade, linguagem e vocabulário, capazes de viabilizarem a representação de artigos científicos que favoreça a recuperação por assunto, no contexto dos periódicos científicos.

\section{Referências}

ANDRADE, Mariana Acorse Lins de; SABBAG, Deise Maria Antonio. Política de indexação: um estudo nas Bibliotecas Públicas do Estado do Rio de Janeiro. Biblioteca Escolar em Revista, Ribeirão Preto, v. 5, n. 2, p. 75-97, 2017.

ANDREATTO, Maria Regina. Periódicos da Ciência da Informação em acesso aberto: análise da indexação. 2010. 55 f. Trabalho de conclusão de curso (Graduação em Biblioteconomia) - Universidade Federal de Santa Catarina, Florianópolis, 2010.

APPEL, André Luiz; ALVES, Larissa de Araújo; BRAGA, Tiago Emmanuel Nunes; RODRIGUES, Thiago Oliveira. Gestão editorial de periódico científico de acesso aberto em consolidação: análise da Revista LatinoAmericana em Avaliação do Ciclo de Vida (LALCA). Ciência da Informação em Revista, Maceió, v. 7, n. esp. Abec, p. 10-22, mar. 2020.

AQUINO, Italo Souza; AQUINO, Itiel Souza. Análise sobre a forma da escrita de palavras-chave em artigos científicos na área de ciências agrárias publicados no período de 1999 a 2011 . Encontros Bibli: revista eletrônica de Biblioteconomia e Ciência da Informação, Florianópolis, v. 18, n. 37, p. 227-238, maio/ago. 2013.

BRANDAU, Ricardo; MONTEIRO, Rosangela; BRAILE, Domingo M. Importância do uso correto dos descritores nos artigos científicos. Revista Brasileira de Cirurgia Cardiovascular, São José do Rio Preto, v. 20, n. 1, p. VII-IX, jan./mar. 2005.

CARNEIRO, Marilia Vidigal. Diretrizes para uma política de indexação. Revista da Escola de Biblioteconomia da UFMG, Belo Horizonte, v. 14, n. 2, p. 221-241, set. 1985.

COORDENAÇÃO DE APERFEIÇOAMENTO DE PESSOAL DE NÍVEL SUPERIOR (Brasil). Capes melhora ferramentas de avaliação da pós-graduação.

Redação CCS/CAPES, Brasília, 18 jul. 2019. Disponível em: https://www.capes.gov.br/36-noticias/9730-capes-melhora-ferramentasde-avaliacao-da-pos-graduacao. Acesso em: 30 ago. 2020.

DIAS, Geneviane Duarte; CERVANTES, Brígida Maria Nogueira. Tratamento temático da informação em periódicos científicos eletrônicos 
na Biblioteconomia e Ciência da Informação. Informação@Profissões, Londrina, v. 2, n. 1, p. 22-38, jan./jun. 2013.

FUJITA, Mariângela Spotti Lopes. A identificação de conceitos no processo de análise de assunto para indexação. Revista Digital de Biblioteconomia e Ciência da Informação, Campinas, v. 1, n. 1, p. 60-90, jul./dez. 2003.

FUJITA, Mariângela Spotti Lopes. A política de indexação para representação e recuperação da informação. In: GIL LEIVA, Isidoro; FUJITA, Mariângela Spotti Lopes. Política de indexação. São Paulo: Cultura Acadêmica; Marília: Oficina Universitária, 2012. p. 17-28.

FUJITA, Mariângela Spotti Lopes; AGUSTÍN-LACRUZ, María del Carmen; TERRA, Ana Lúcia. Knowledge Organization in editorial policies for titles, abstracts and keywords in JCR-indexed journals: an exploratory study in the areas of Information and Communication Sciences. In:

INTERNATIONAL ISKO CONFERENCE, 15., 2018. Anais [...]. Porto: Universidade do Porto, 2018.

FUJITA, Mariângela Spotti Lopes; RUBI, Milena Polsinelli. O ensino de procedimentos de política de indexação na perspectiva do conhecimento organizacional: uma proposta de programa para a educação à distância do bibliotecário. Perspectivas em Ciência da Informação, Belo Horizonte, v. 11 , n. 1, p. 48-66, jan./abr. 2006.

FUJITA, Mariângela Spotti Lopes; SANTOS, Luciana Beatriz Piovezan dos. Política de indexação em bibliotecas universitárias: estudo diagnóstico e analítico com pesquisa participante. TransInformação, Campinas, v. 28, n. 1, p. 59-76, jan./abr. 2016.

GIL LEIVA, Isidoro. Aspectos conceituais da indexação. In: GIL LEIVA, Isidoro; FUJITA, Mariângela Spotti Lopes (ed.). Política de indexação. São Paulo: Cultura Acadêmica; Marília: Oficina Universitária, 2012. p. 31-105.

GOMES, Cristina Marques. Comunicação científica: alicerces, transformações e tendências. Covilhã: Livros LabCom, 2013.

GOMES, Sonia Pedrozo; SANTOS, Maria Aparecida de Lourdes Castro. Avaliação de um periódico na área de Medicina Tropical. Ciência da Informação, Brasília, v. 30, n. 2, p. 91-100, maio/ago. 2001.

GOMES, Valdir Pereira. O editor da revista científica: desafios da prática e da formação. Informação \& Informação, Londrina, v. 15, n. 1, p. 147-172, jun./jul. 2010. 
GUIMARÃES, José Augusto Chaves. Políticas de análisis y representación de contenido para la gestión del conocimiento em las organizaciones.

Scire, Zaragoza, v. 6, n. 2, p. 49-58, jul./dic. 2000.

LANCASTER, F. W. Indexação e resumos: teoria e prática. 2. ed. Tradução de Antonio Agenor Briquet de Lemos. Brasília: Briquet de Lemos, 2004.

MARCONDES, Carlos Henrique. O papel das relações semânticas na organização e representação do conhecimento em ambientes digitais. In: SILVA, Fabiano Couto Corrêa da; SALES, Rodrigo de (org.). Cenários da Organização do Conhecimento: linguagens documentárias em cena. Brasília: Thesaurus, 2011. p. 129-168.

MARCONDES, Carlos Henrique; MENDONÇA, Marília Alvarenga Rocha. Avaliação de periódicos eletrônicos acadêmicos brasileiros: uma proposta de método baseado na análise de links para o site do periódico. TransInformação, Campinas, v. 18, n. 2, p. 123-130, maio/ago. 2006.

MIGUÉIS, Ana; NEVES, Bruno; SILVA, Ana Luísa; TRINDADE, Álvaro; BERNARDES, José Augusto. A importância das palavras-chave dos artigos científicos da área das Ciências Farmacêuticas, depositados no Estudo Geral: estudo comparativo com os termos atribuídos na MEDLINE. InCID: Revista de Ciência da Informação e Documentação, Ribeirão Preto, v. 4, n. 2, Ed. esp., p. 112-125, jul./dez. 2013.

MIRANDA, Dely Bezerra de; PEREIRA, Maria de Nazaré Freitas. O periódico científico como veículo de comunicação: uma revisão de literatura. Ciência da Informação, Brasília, v. 25, n. 3, p. 375-382, set./dez. 1996.

PINHEIRO, Lena Vania Ribeiro. Constituição epistemológica e social da comunicação científica no Brasil. In: PINHEIRO, Lena Vania Ribeiro; OLIVEIRA, Eloisa da Conceição Príncipe de (org.). Múltiplas facetas da comunicação e divulgação científicas: transformações em cinco séculos. Brasília: IBICT, 2012. p. 115-148.

RODRIGUES, Rosângela Schwarz; FACHIN, Gleisy Regina Bories. A comunicação científica e o uso de portais: estudo. In: ENCONTRO NACIONAL DE PESQUISA EM CIÊNCIA DA INFORMAÇÃO, 9., São Paulo. Anais [...]. São Paulo: USP, 2008.

RUBI, Milena Polsinelli; FUJITA, Mariângela Spotti Lopes. Elementos de política de indexação em manuais de indexação de sistemas de informação especializados. Perspectivas em Ciência da Informação, Belo Horizonte, v. 8, n. 1, p. 66-77, jan./jun. 2003. 
SANTIAGO, Márcio Sales. Redes de palavras-chave para artigos de divulgação científica da Medicina: uma proposta sob a perspectiva da Terminologia. In: SIMPÓSIO INTERNACIONAL DE ESTUDOS DE GÊNEROS TEXTUAIS, 5., 2009. Anais [...]. Caxias do Sul: Universidade de Caxias do Sul, 2009.

SERRA, Fernando Antonio Ribeiro; FERREIRA, Manuel Aníbal Silva Portugal Vasconcelos. O título, resumo e palavras-chave dos artigos. Revista IberoAmericana de Estratégia, v. 13, n. 4, out./dez. 2014.

SEVERINO, Antônio Joaquim. Metodologia do trabalho científico. 23. ed. rev. atual. São Paulo: Cortez, 2014.

SILVA, Deise Deolindo; ALMEIDA, Cátia Cândida de; GRÁCIO, Maria Cláudia Cabrini. Avaliação científica de periódico em Ciências Sociais: junção dos indicadores Fator de Impacto e índice h. In: ENCONTRO BRASILEIRO DE BIBLIOMETRIA E CIENTOMETRIA, 6., 2018. Anais [...]. Rio de Janeiro: UFRJ, 2018.

SILVEIRA, Lúcia da; MACHADO, Andreia de Bem; KROEFF, Marcia Silveira; SPUDEIT, Daniela Fernanda Assis de Oliveira. Serviço de indexação no Portal de Periódicos da UFSC: estratégia para a indexação de periódicos no Scielo. Revista $A C B$ : Biblioteconomia em Santa Catarina, Florianópolis, v. 23, n. 1, p. 69-91, dez./mar. 2018.

SIMÕES, Maria da Graça; MARTÍNEZ-ÁVILA, Daniel; RODRÍGUEZ-BRAVO, Blanca; ALMEIDA, Patricia de; EVANGELISTA, Isadora Victorino.

Approaches to the concepts of exhaustivity and specificity in ISKO International meeting proceedings: 2000-2017. In: RIBEIRO, Fernanda; CERVEIRA, Maria Elisa (ed.). Challenges and Opportunities for Knowledge Organization in the Digital Age: Proceedings of the Fifteenth International ISKO Conference 9-11 July 2018 Porto, Portugal. Würzburg, Germany: Ergon, 2018, p. 58-65.

SMIRAGLIA, Richard P. Keywords, Indexing, Text Analysis: An Editorial. Knowledge Organization, v. 40, n. 3, p. 155-159.

VALERIO, Palmira Moriconi; PINHEIRO, Lena Vania Ribeiro. Da comunicação científica à divulgação. TransInformação, Campinas, v. 20, n. 2, p. 159-169, maio/ago. 2008. 